\title{
OBITUARY
}

\section{John AleXander MacMillan}

ALL our readers will be distressed to learn of the sudden death at the age of 67 of John $\stackrel{\otimes}{\mathscr{Q}}$ Alexander MacMillan. His life was marked by great achievement both in the furtherance of ophthalmology and in building up a host of friendships not only in Canada but also among his colleagues all over the world. He graduated from McGill University in 1906, took his post-graduate training in ophthalmology at the Manhattan Eye and $\vec{\omega}$ Ear Infirmary in New York and, after spending a considerable time studying in London Germany, and Austria, returned to his home in Montreal where he spent the remainder $\frac{0}{0}$ of his professional life. In 1914 he joined the R.A.M.C., and he served overseas in the 3rd Canadian General Hospital, becoming Consultant in Ophthalmology to the or Corps. In 1940 he became Ophthalmologist-in-Chief to the Royal Victoria Hospital in $\dot{\omega}$ Montreal, and in 1941, Professor of Ophthalmology at McGill University.

His life was indeed a full one. An accomplished surgeon and an unusually good teacher, he conducted a large private practice with singular success, and at the same time added considerably to the clinical advancement of his specialty and took much $\vec{z}$ interest in its social and academic aspects; he was, for example, elected a Fellow of the American Society of Ophthalmology, a President of the Canadian Ophthalmological $\overrightarrow{0}$ Society, and Vice-President of the Pan-American Congress of Ophthalmology. But greater than these, his rare spiritual qualities and his kindly sympathy, expressed with a characteristic natural humility and charm, will make him live long in the memories of those who were privileged to know him.

\section{Karl Wessely}

OUR readers will be sad to learn of the recent death of Karl Wessely, one of the foremost ophthalmologists of the last generation and of this. A student in Berlin and Heidelberg, he became Professor of Ophthalmology in Munich, where, apart from a temporary $\frac{0}{0}$. expulsion because the Nazi government disliked a partially Jewish ancestry, he lived and :worked until his death. His original researches covered most aspects of ophthalmology, 3 . from his early classical work on the fundamental question of the intra-ocular pressure which $\delta$ was done contemporaneously with that of Starling and Henderson in Great Britain, to 3 his last great contribution in editing the eleventh volume-on the eye-of Henke and 0 Lubarsch's Handbuch der speziellen pathologischen Anatomie und Histologie (1928-37) A great clinician and a great surgeon, and one of the most modest and delightful of men. he died fully honoured and appreciated not only in his own country but throughout the world.

WE regret to announce the death of Mr. Alexander Bruce Roxburgh, F.R.C.S. consulting ophthalmic surgeon to the London Hospital, who died at his home, Locks $\widetilde{\complement}$ Heath, Hants, on March 17, 1953. An obituary notice will appear in the next issue $\stackrel{\oplus}{?}$ of this Journal. 